\title{
Usefulness of the Obesity Surgery Mortality Risk Score (OR-MRS) in choosing the laparoscopic bariatric procedure
}

\author{
Mikołaj Orłowski, Michał R. Janik, Krzysztof Paśnik, Emil Jędrzejewski \\ Department of General Surgery, Oncologic, Metabolic and Thoracic Surgery, Military Institute of Medicine, Warsaw, Poland
}

Videosurgery Miniinv 2015; 10 (2): 233-236

DOI: $10.5114 /$ wiitm.2015.52390

\begin{abstract}
Introduction: The most popular scale to stratify the postoperative risk is the Obesity Surgery Mortality Risk Score (OS-MRS). The design and ease of interpretation make the scale a potential tool for clinical use.

Aim: To evaluate the usefulness of the OS-MRS scale in the enrollment of patients for laparoscopic bariatric procedures, including laparoscopic sleeve gastrectomy (LSG) and laparoscopic Roux-en-Y gastric bypass (LRYGB).

Material and methods: The medical records of patients who underwent LSG or LRYGB due to obesity between January 2010 and December 2010 were reviewed retrospectively. The decision of choosing the surgical procedure was made on the basis of OS-MRS risk category. The primary endpoint of this study was the 90-day mortality, and the secondary endpoint was the presence of major complications.

Results: There were 107 patients including 66 women and 41 men. The OS-MRS classes were A (48\%), B (47\%) and $C(5 \%)$. The LSG was applied to patients with higher body mass index and to patients of class $C$. The secondary endpoints occurred in 6 patients, distributed in $10 \%$ of class $A, 2 \%$ of class $B$ and $0 \%$ of class $C$ patients $(p<0.05)$. In 5 of 6 cases the endpoint was observed after LRYGB. Fatal cases were not observed.

Conclusions: The OS-MRS can be a useful clinical tool for choosing the appropriate laparoscopic bariatric procedure, depending on the risk of postoperative complications. Low risk of postoperative complications should not lower the watchfulness of the surgeon.
\end{abstract}

Key words: obesity, bariatric surgery, postoperative complications, Obesity Surgery Mortality Risk Score.

\section{Introduction}

Laparoscopic bariatric surgery is superior to an open approach [1, 2]. However, minimally invasive procedures do not eliminate the risk of complications. Patients scheduled for surgical weight loss differ in many aspects, including severity of obesity and presence of comorbidities, making them a heterogeneous population with varying risk for postoperative complications. Thus, a scale is needed to stratify the post-operative risk in bariatric patients to allow for the best surgical procedure to be chosen or bariatric methods altered for a particular patient [3]. Previous attempts to create this type of scale have yielded the most popular tool for stratification of postoperative risk, the Obesity Surgery Mortality Risk Score (OSMRS), described by DeMaria et al. [4]. The OS-MRS assigns 1 point to each of 5 preoperative variables, and the class of the risk assigned is dependent on the total points obtained [5]. The OS-MRS has been validated in previous studies [5, 6]. The advantage of the OS-MRS is its simple design and ease of interpretation, which makes it a potential tool for clinical use.

\section{Aim}

The aim of this study is to evaluate the clinical usefulness of the OS-MRS scale in the enrollment 
of patients for laparoscopic bariatric procedures, including laparoscopic sleeve gastrectomy (LSG) and laparoscopic Roux-Y gastric bypass (LRYGB).

\section{Material and methods}

Data from 107 patients who underwent minimally invasive weight loss procedures were retrospectively analyzed. All patients underwent surgery from January 2010 to December 2010 in the Department of General Surgery. There were 66 (62\%) females and $41(38 \%)$ males. All patients who underwent surgery met the following 1991 National Institutes of Health Consensus Conference guidelines for bariatric surgery: body mass index (BMI) $\geq 35 \mathrm{~kg} / \mathrm{m}^{2}$ with associated co-morbidities or BMI $\geq 40 \mathrm{~kg} / \mathrm{m}^{2}$ with or without co-morbidities [7]. The minimally invasive bariatric procedures included LSG and LRYGB, and patients were evaluated prior to surgery by a multidisciplinary team. The risk of postoperative complications was assessed using the OS-MRS scale. One point was assigned to each of 5 preoperative variables including body mass index (BMI) $\geq 50 \mathrm{~kg} /$ $\mathrm{m}^{2}$, male gender, hypertension, known risk factors for pulmonary embolism or "PE" (previous thromboembolism, preoperative vena cava filter, hypoventilation, and pulmonary hypertension), and age $\geq 45$ years. Patients were divided into four categories according to the OS-MRS results. The class of the risk assigned to each patient was dependent on the total points obtained. A score of zero or one point = class A; two or three points = class B; and four or five points = class C [5]. The choice of surgical procedure was made on the basis of the OS-MRS risk category assigned to a particular patient and the experience of the surgical team. The main endpoint was 90-day mortality. The occurrence of one of the following events was considered as the secondary endpoint: dehiscence of a staple-line, intraperitoneal hemorrhage, or ileus.

\section{Statistical analysis}

To assess the significance of the observed differences in the prevalence of the analyzed endpoints within each group, the $\chi^{2}$ test and Fisher's exact test were used. SAS 9.3 software was used for statistical analysis.

\section{Results}

Demographic characteristics of patients are presented in Table I.

\section{Class A}

Class A consisted of 52 patients aged 23 to 54 years (mean: $36 \pm 7$ ). Twenty-three patients were female and 29 were male. Their mean BMI was 45.1 $\pm 7.2 \mathrm{~kg} / \mathrm{m}^{2}$. Most of the patients underwent LSG $(n=31)$, which was used more frequently for male patients than for female patients (20 vs. 11). In the group of patients qualified for LSG the mean age was $36 \pm 6$ years and the mean BMI was $48.1 \pm 7.9 \mathrm{~kg} / \mathrm{m}^{2}$. In class A, 21 patients underwent LRYGB. Twelve of

Table I. Characteristics of patients adjusted for class of risk

\begin{tabular}{|c|c|c|c|c|c|}
\hline \multirow[t]{2}{*}{ Class of risk } & \multirow[t]{2}{*}{ Characteristic of patients } & \multicolumn{2}{|c|}{ Type of surgery } & \multirow[t]{2}{*}{ Total } & \multirow[t]{2}{*}{ Value of $p$} \\
\hline & & LSG & LRYGB & & \\
\hline \multirow[t]{3}{*}{ A } & Sex (female/male), $n$ & $11 / 20$ & $12 / 9$ & $23 / 29$ & NS \\
\hline & Age [years] & $36 \pm 6$ & $36 \pm 7$ & $36 \pm 7$ & NS \\
\hline & BMI $\left[\mathrm{kg} / \mathrm{m}^{2}\right]$ & $48.1 \pm 7.9$ & $40.7 \pm 2.4$ & $45.1 \pm 7.2$ & $<0.05$ \\
\hline \multirow[t]{3}{*}{ B } & Sex (female/male), $n$ & $14 / 6$ & $25 / 5$ & $39 / 11$ & NS \\
\hline & Age [years] & $42 \pm 5$ & $45 \pm 11$ & $43 \pm 6$ & NS \\
\hline & $\mathrm{BMI}\left[\mathrm{kg} / \mathrm{m}^{2}\right]$ & $48.5 \pm 7.0$ & $42.3 \pm 4.6$ & $44.8 \pm 6.4$ & $<0.05$ \\
\hline \multirow[t]{3}{*}{ C } & Sex (female/male), $n$ & $4 / 1$ & $0 / 0$ & $4 / 1$ & - \\
\hline & Age [years] & $56 \pm 3$ & - & $56 \pm 3$ & - \\
\hline & BMI [kg/m²] & $51.6 \pm 6.6$ & - & $51.6 \pm 6.6$ & - \\
\hline
\end{tabular}

NS - Not significant. 
these patients were female and 9 were male. The mean age of patients qualified for LRYGB was $36 \pm 7$ years, and the mean BMI was $40.7 \pm 2.4 \mathrm{~kg} / \mathrm{m}^{2}$. The difference in the mean BMI values between the LSG and LRYGB groups was statistically significant. The endpoint was observed in 5 patients including 3 patients following LRYGB and 2 following LSG. Among the patients who received LRYGB, we observed 2 cases of a dehiscence of the staple-line and 1 case of ileus. Two patients developed a dehiscence of the staple-line after LSG (Table II).

\section{Class B}

Class B consisted of 50 patients 18 to 60 years of age (mean age: $43 \pm 6$ years). There were 39 female patients and 11 male patients with a mean BMI of $44.8 \pm 6.4 \mathrm{~kg} / \mathrm{m}^{2}$. Most of the patients underwent LRYGB $(n=30)$, including 25 females and 5 males. The mean age of these patients was $45 \pm 11$ years, and the mean BMI was $42.3 \pm 4.6 \mathrm{~kg} / \mathrm{m}^{2}$. Twenty of the patients from class $B$ underwent LSG, including 14 females and 6 males. The mean age of patients who underwent LSG was $42 \pm 5$ years, and the mean BMI was $48.5 \pm 7.0 \mathrm{~kg} / \mathrm{m}^{2}$. The difference in the mean $B M I$ values between the LRYGB and LSG groups was statistically significant. The endpoint was observed in 1 patient who developed intraperitoneal hemorrhage after LRYGB. No endpoints were observed in the patients who underwent LSG (Table II).

\section{Class C}

Class $C$ consisted of 5 patients 53 to 63 years of age (mean: $56 \pm 3$ years) including 4 females and 1 male. The mean $\mathrm{BMI}$ of the patients assigned to class C was $51.6 \pm 6.6 \mathrm{~kg} / \mathrm{m}^{2}$, and all patients underwent LSG. These patients were not qualified for LRYGB. No endpoints were observed in this group.

There were no fatal cases in this study. The distribution of the endpoints by OS-MRS class was not statistically significant.

\section{Discussion}

Sleeve gastrectomy (SG) and Roux-Y gastric bypass (RYGB) are currently the most popular bariatric procedures in Poland [8]. These procedures support a significant reduction of body mass, BMI and waist and hip circumference [9]. Considering the increasing popularity of minimally invasive surgery, most of the mentioned procedures are performed via laparoscopy.

In the case of LSG and LRYGB, the most common complications include dehiscence of a staple-line, intraperitoneal hemorrhage and ileus due to sleeve or anastomosis stenosis. These events were considered as the endpoints of our study. According to the literature, the risk of early mortality after bariatric surgery ranges from $0.1 \%$ to $0.6 \%$ [10-12]. In the present study, the mortality rate was $0 \%$. No fatal cases were observed this study because the proper bariatric procedure was selected for each patient. The endpoint risk was $5 \%$, which is similar to data presented in another paper assessing the OS-MRS scale as a clinically useful tool for patients seeking laparoscopic bariatric procedures [13]. Surprisingly, most of the observed endpoints were noticed in class A patients. Considering the type of observed complications, this may be the result of technical mistakes. In our opinion, there is also a problem of low watchfulness in patients assessed as low-risk. No endpoints were observed in class C patients, again due to proper procedure choices. None of the patient from class $C$ underwent LRYGB. This decision was sound, considering that the majority of observed complications followed LRYGB. Some discussion has centered on LSG as a procedure for class C patients [14], and our results support LSG as a proper procedure for this group of patients, especially as there is evidence for the effectiveness of LSG in the subgroup of patients with $\mathrm{BMI} \geq 50 \mathrm{~kg} / \mathrm{m}^{2}$ [15].

Unfortunately, the main limitation of this study is the small number of patients enrolled. The main

Table II. Distribution of secondary endpoints

\begin{tabular}{|lcccccc|}
\hline Endpoint & \multicolumn{3}{c}{ Class A } & \multicolumn{2}{c}{ Class B } & Class C \\
\cline { 2 - 7 } & LRYGB & LSG & LRYGB & LSG & LRYGB & LSG \\
\hline Dehiscence of staple line & 2 & 2 & 0 & 0 & - & 0 \\
\hline Intraperitoneal hemorrhage & 0 & 0 & 1 & 0 & - & 0 \\
\hline Ileus & 1 & 0 & 0 & 0 & - & 0 \\
\hline
\end{tabular}


Polish bariatric centers should set up a national program to monitor bariatric patients, including a system for reporting post-operative complications. Collection of these data will help to improve the care of bariatric patients in Poland and will be useful to determine the best surgical procedure depending on the post-operative risk.

\section{Conclusions}

The OS-MRS can be a useful clinical tool for choosing the proper laparoscopic bariatric procedure, depending on the risk of postoperative complications. Considering the simplicity of the OS-MRS, it can be widely applied when qualifying patients for surgical treatment. However, it should be emphasized that low risk of postoperative complications should not lower the watchfulness of the surgeon.

\section{Conflicts of interest}

The authors declare that they have no conflict of interest.

All procedures performed in studies involving human participants were in accordance with the ethical standards of the institutional and/or national research committee and with the 1964 Helsinki Declaration and its later amendments or comparable ethical standards.

Informed consent was obtained from all individual participants included in the study.

\section{References}

1. Nguyen NT, Lee SL, Goldman C, et al. Laparoscopic versus open gastric bypass: a randomized study of outcomes, quality of life, and costs. Ann Surg 2001; 234: 279-89.

2. Paluszkiewicz R, Kalinowski P, Wróblewski T, et al. Prospective randomized clinical trial of laparoscopic sleeve gastrectomy versus open Roux-en-Y gastric bypass for the management of patients with morbid obesity. Videosurgery Miniinv 2012; 7 : 225-32.

3. Kaska $Ł$, Proczko M, Stefaniak T, et al. Redesigning the process of laparoscopic sleeve gastrectomy based on risk analysis resulted in 100 consecutive procedures without complications. Videosurgery Miniinv 2013; 8: 289-300.

4. DeMaria EJ, Portenier D, Wolfe L. Obesity surgery mortality risk score: proposal for a clinically useful score to predict mortality risk in patients undergoing gastric bypass. Surg Obes Relat Dis 2007; 3: 134-40.

5. DeMaria EJ, Murr MM, Byrne TKM, et al. Validation of the Obesity Surgery Mortality Risk Score in a multicenter study proves it stratifies mortality risk in patients undergoing gastric bypass for morbid obesity. Ann Surg 2007; 246: 578-84.
6. Efthimiou E, Court O, Sampalis J, et al. Validation of Obesity Surgery Mortality Risk Score in patients undergoing gastric bypass in a Canadian center. Surg Obes Relat Dis 2009; 5: 643-7.

7. Fried M, Yumuk V, Oppert JM, et al. Interdisciplinary European Guidelines on metabolic and bariatric surgery. Obes Facts 2013; 6: 449-68.

8. Buchwald H, Oien DM. Metabolic/bariatric surgery worldwide 2011. Obes Surg 2013; 4: 427-36.

9. Jastrzębska-Mierzyńska M, Ostrowska L, Hady HR, et al. The impact of bariatric surgery on nutritional status of patients. Videosurgery Miniinv 2015; 10: 115-24.

10. The Longitudinal Assessment of Bariatric Surgery (LABS) Consortium. Perioperative safety in the longitudinal assessment of bariatric surgery. N Engl J Med 2009; 361: 445-54.

11. DeMaria EJ, Pate V, Warthen M, et al. Baseline data from American Society for Metabolic and Bariatric Surgery-designated Bariatric Surgery Centers of Excellence using the Bariatric Outcomes Longitudinal Database. Surg Obes Relat Dis 2010; 6: 347-55.

12. Szewczyk T, Janczak P, Duszewski M, et al. Technical problems in laparoscopic sleeve gastrectomy. Videosurgery Miniinv 2009; 4: 95-101.

13. Sarela Al, Dexter SP, McMahon MJ. Use of the obesity surgery mortality risk score to predict complications of laparoscopic bariatric surgery. Obes Surg 2011; 21: 1698-703.

14. Lancaster RT, Hutter MM. Bands and bypasses: 30-day morbidity and mortality of bariatric surgical procedures as assessed by prospective, multi-center, risk-adjusted ACS-NSQIP data. Surg Endosc 2008; 22: 2554-63.

15. Lehmann A, Bobowicz M, Lech P, et al. Comparison of percentage excess weight loss after laparoscopic sleeve gastrectomy and laparoscopic adjustable gastric banding. Videosurgery Miniinv 2014; 9: 351-6.

Received: 22.01.2015, accepted: 8.03.2015. 